\title{
Chapter 8 \\ Carbon Finance and Emission Trading in Mexico: Building Lessons \\ from the CDM Experience and FOMECAR (Mexican Carbon Fund)
}

\section{Simone Lucatello and José Eduardo Tovar Flores}

\begin{abstract}
A more general lesson from the past decade is that climate policy and carbon initiatives such as ETS and carbon pricing are not static concepts, but are instead constantly evolving and building upon previous experiences. The vision of a single, top-down global trading system has shifted toward the reality of various single and regional trading system programmes. Building a national emission trading system in Mexico will surely pass through processes and experiences that the country has somehow undertaken from the Kyoto Protocol (KP) in 2005, particularly with the Clean Development Mechanism (CDM), the Mexican Carbon Fund (FOMECAR) and their legacy. Additional design elements or provisions must be prepared under the new ETS in Mexico: regulation will possibly include definitions, scope, compliance obligation, legal procedures and other necessary provisions such as the allocation of permits. However, in order to start the process, important questions on financing the initiative and accompanying the development of an ETS will go through a finance support scenario. Thus, who is going to finance the starting process for allocating emissions, financing bonds and other design issues for the implementation of the Mexican ETS? Who will be financing and offering technical cooperation to follow up on eligible projects for the ETS and who will be supporting education and information activities about ETS implementation? Those and other questions will be addressed in this article, in the light of international and regional experiences.
\end{abstract}

Keywords Carbon finance $\cdot$ International cooperation $\cdot$ Clean development mechanism $\cdot$ FOMECAR

\footnotetext{
S. Lucatello (凶)

Instituto Mora/CONACYT, Mexico City, Mexico

e-mail: slucatello@institutomora.edu.mx

\section{J. E. T. Flores}

Eosol Energy de México, S.A.P.I. de C.V., Mexico City, Mexico

e-mail: eduardo.tovar@eosolenergy.com
} 


\section{Introduction: The Stages of the Carbon Markets. Evolution and Lessons Learned}

The implementation of a future Mexican ETS will go through different phases, and it will be working in parallel with market mechanisms rules for climate change mitigation that were adopted during COP-25 in 2019. As carbon market actions were built upon many years of intense negotiations and have evolved overtime, it is crucial to understand the legacy of the market mechanisms and learn from past international experiences to better understand the Mexican ETS outreach.

In a synthetic attempt to understand carbon markets' recent history, we can identify four clear stages and periods of evolution. Building on Michaelowa's time-lapse model, the first period refers to the birth and growth of carbon markets in the mid90s. The second one, named the "gold rush", stretches from entry into force of the Kyoto Protocol (KP) in 2005 until 2012. Then, a fragmentation period occurs during the Second commitment period of the KP until the Paris Agreement in 2015 (20092015). And finally, the ultimate period defined is the post-Paris implementation, occurring during the period 2015-2024.

Each of these stages was clearly defined by key market agreements as well as regulatory procedures constantly interacting with international negotiations and the various COPs outcomes. The following section will briefly revise each one of the stages and provide some comments on lessons learned.

Concerning the first stage, from 1997 to 2004, the international community saw the genesis of the carbon markets and their design. Carbon markets represent a technical tool that can help governments to achieve their commitments to reducing GHG emissions and fight climate change impacts. Recently, the UNFCCC and the Kyoto Protocol have served as the international legal references under which the idea of carbon markets was born and developed. The starting point was Article 4.2 of the UN Framework Convention on Climate Change (UNFCCC) with its rule on "Joint Implementation" (JI) for Greenhouse Gas (GHG) mitigation by several countries. Taking up previous experiences in the US and South-East Asia, UNFCCC negotiators and experts from different countries began to come up with recommendations for market mechanisms. Even though differences among the way of dealing with climate change impacts and financing climate actions among developed and developing nations, the first conference of the parties in 1995 decided to start a pilot phase of the "Activities Implemented Jointly" (AIJ) lasting until 2000 without generating credit issuance (Michaelowa et al. 2019). This action paved the way for testing different market design options in many countries around the world and the first developing country to implement the AIJ was in Latin America, more precisely Costa Rica in the issues of wind, hydro and reforestation.

This period also saw the development of an important milestone for the carbon markets, meaning a tool to standardize units of GHG emission reductions that can be traded, sold, retired or transferred (EU-ETS 2015). In other words, offsetting and the issuance of a carbon credit measured in $\mathrm{CO} 2$ tons was put in the table of the negotiations. The use of carbon credits within different schemes, like Certified 
Emission Reductions (CERs), could be used as offsets under ETS or domestic carbon pricing (World Bank 2010). The foundations of the carbon markets were laid together with other measures adopted during international negotiations, such as technology transfer, innovation, research and development on low-carbon technologies/measures through increasing domestic carbon prices, among others.

With the adoption of Kyoto Protocol (KP) in 1997, the international community adopted some important procedures for developed and emerging economies like the introduction of emissions reduction targets and mitigation goals through emissions allowances_-in amount units (AAUs) — distributed to several countries or using market mechanisms to exchange AAUs through emission reduction projects. The market mechanisms were defined as the Joint Implementation (JI) for Annex B countries and the Clean Development Mechanism (CDM) in non-Annex B countries. This last one should generate Certified Emissions Reductions (CERs). Among them, the CDM proposed by Brazil established itself as the most agreed upon scheme accepted in the weeks preceding the Kyoto Conference of Parties in 1997 (Shishlov et al. 2016).

Technicalities around the CDM project cycle and sophistication of the crediting system evolved from the development of a Project Design Document (PDD), validation by an independent auditor, project registration, monitoring of emissions reductions, independent verification and CER issuance among others (Lucatello 2011). Within the projects' documentation process, an important discussion includes the use of methodologies, measuring sustainable development co-benefits among other issues and more generally, the design process for implementing the CDM (Shishlov and Bellassen 2016).

In this first stage of the evolution of carbon markets, the main arguments from the economics and policy of climate change have been set. Emissions trading and its ability to cap emissions at a desired level may make it possible to achieve abatement of emissions at the lowest overall cost as well as provide the right incentives for firms to innovate in environmentally friendly technologies. On the other, they could generate enough revenues for financing climate actions and promoting sustainable development in developing countries. This first CDM phase offers clearly important lessons for the current process of designing the ETS mechanism in Mexico.

\section{The "Golden Era" of the Carbon Markets: 2005-2011}

The period between 2005 and 2011 saw strong growth of international carbon markets, triggered by the European Union decision in 2004 to allow the use of credits from CDM and JI for compliance under the EU Emissions Trading Scheme (ETS). Under these circumstances, the mechanisms gained sudden popularity in the private sector and carbon markets grew much more than originally expected (Michaelowa et al. 2019).

Ten years after the adoption of the KP and five years from its entry into force, CDM became an immense global market, having more than 5,000 projects registered and a 
value of several billion Euros (DTU/UNEP 2011). In this sense, the CDM has been a great success in developing a new market for GHG emission reduction projects and providing tools for mitigation actions worldwide (World Bank 2012). CDM had been growing in many developing countries up to 2011, but it was concentrated in few geographical areas, such as Asia and Latin America. China dominates the market both in number of CDM and volume of CERs (40\%), followed by India (14\%), Brazil (8\%), Mexico (6\%) and South Korea (5\%). Thus, $82 \%$ of expected CDM emission reductions by 2012 were concentrated in just five countries (UNCTAD 2009). However, the CDM has been strongly criticized for many other reasons, not only due to the difficulties in implementation but also for not delivering on its environmental and sustainable development objectives among other issues (Wara 2008). The CDM has recently come to terms with its future structure (post-Kyoto 2012) and its structural inadequacies: part-time governing bodies, inappropriate division of responsibilities and, among other factors, neglect of due process as well as lack of transparency. Those are also lessons learned for the implementation of an ETS.

In terms of governance, the CDM was also characterized by the involvement of private actors. On one side, private actors have a role in the rule-making process because they can submit proposals for new CDM methodologies and sectors of analysis. Additionally, all private stakeholders of CDM projects may publicly participate in project design documents and its content. Private actors are instrumental for the CDM implementation because a variety of stakeholders like consultancies, certification companies, and project owners themselves, among others, are the ones actually implementing emission reduction measures. This systematic involvement of private actors in governance arrangements has raised many expectations of higher effectiveness and efficiency in the achievement of governance results (Börzel and Risse 2002).

Crucial to an understanding of the need to reform the CDM is that these problems do not result from the lack of efforts from any part of those working within the system but are signs of systemic limitations of flexible mechanisms and the overall climate change environmental architecture, including the KP and the UNFCCC itself. The Conference of the Parties (COP) of the UNFCCC and the Members of the Protocol (MOP) — which regulate and monitor the implementation of the Protocolhave authority over the CDM and its guidelines and decide on recommendations concerning CDM rules. COP/MOP also decides on the designation of the Designated Operational Entities (DOEs), provisionally certified by the Executive Board (EB). It reviews annual EB reports and regional and sub-regional distribution of DOEs and project activities. Finally, it helps obtain funding for CDM project activities (Lucatello 2011).

In this regard, the CDM has been a big success in developing a new market for GHG emission reduction projects in developing countries. It is widely acknowledged as a mechanism that has changed emission trends in some industries and enabled entities in developing countries to participate in the emerging global carbon market. It has also contributed to raising awareness of public and private entities for climate change. Although treated further in the book, those concerns constitute the core of proposals for the ETS scenarios after CDM implementation. 
An important legacy of the CDM was that these projects helped developing countries to build technical capacity regarding structuring of emissions reduction projects and carbon accounting (Mehling and Mielke 2012). A common view among experts points to the fact that capacity building for low-carbon transition in developing countries was one of the most important impacts of CDM (Spalding-Fecher 2011).

Especially in large emerging economies like India, China, Mexico and Brazil an important group of experts like consultants and different stakeholders emerged to play different roles in the growing carbon markets. Private financial institutions were actively participating in the carbon markets as intermediaries, enhancing market liquidity (Weber and Darbellay 2011), mostly in bigger development economies. As demonstrated by several studies (Haigh 2011), carbon funds can play a fundamental role in pooling demand for credits. Moreover, carbon funds were instrumental during this phase to enable development banks to support CDM dissemination.

In critical terms, this phase of the evolution of carbon markets was characterized by strong criticism about economic efficiency, environmental integrity and contribution to sustainable development (Lucatello 2011). At some point, the CDM was considered an ineffective instrument with limited results in reducing global GHG emissions and its mayor success was that of being an economic instrument to increase revenues for just a number of restricted developed countries. Although treated further in the book, those concerns must be taken into account when considering ETS scenarios implementation.

\section{The Fall of CDM and Market Fragmentation (2011-2015)}

International negotiations around climate change suffered severe blows during COP15 in Copenhagen (2009) when international commitments to emission reductions almost derailed. As a result of that, subsequent COPs like the one in Cancun in 2010 and through to COP21 in Paris (2015) were characterized by important changes around the reforms of the CDM and more general on the KP's flexible mechanism.

The project focus of CDM was soon considered outdated. Some evolutions took place such as the introduction of the concept of NAMA, which escalated the CDM projects. Nationally Appropriate Mitigation Actions (NAMAs) are policies, programmes and projects that developing countries undertake to contribute to GHG emission reduction efforts. They are central instruments in addressing emission reductions in developing economies. Though the CDM is still existing and functioning, NAMAs slowly substituted the system of projects set by the CDM by moving to complex and larger scale projects mainly in renewable energies.

NAMAs do not represent a legal obligation under the UNFCCC since they represent voluntary actions taken by developing countries to reduce GHG emissions to levels below those of "Business as Usual" (BAU) (Bakhtiari et al. 2015). A common characteristic of NAMAs is that they constitute a transformational change for a given sector of the economy and they provide support for such change. 
In the case of Mexico, NAMA projects during this phase combined different political agendas of the Mexican Government: combating climate change, fostering sustainable urban development and housing, as well as improving the quality of life of low-income groups in the social housing sector. An important and flagship case was the Mexican housing NAMA that created a project for transforming the housing sector by including diverse groups of actors and institutions. The Housing NAMA included over 40,000 houses in the energy efficiency sector and was backed by the Mexican National Housing Commission (CONAVI) though subsidies from 2013 to 2017. Major achievements included great impact on national emission reductions in line with the National Special Plan for Climate Change (PECC).

A crucial lesson for this particular NAMA and others implemented in Mexico during this phase is that these projects worked with both domestic and international financing, typically through existing lines of credits from national development banks. In a second stage, NAMAs that used domestic sources could leverage international funding, ideally from institutions that are already active in the country such international cooperation agencies. In such cases, the creation of an enabling environment for private/corporate financing were part of the design process from the outset through the end.

During this period known as "fragmentation", volatility and decline of carbon markets due to the falling demand for carbon credits were also crucial issues. Additionally, as a second major issue, voluntary markets started to gain domain within the climate change arena. Concerning the voluntary carbon markets, they have emerged in various jurisdictions, mostly in North America. However, the total volume of credits traded in voluntary markets is only a small percent of the international and national compliance markets (Hamrick and Galant 2017).

During this period, the supply of carbon credits rapidly began saturating aggregate demand - from the EU-ETS and national governments-which was estimated at between 1.6 and 1.9 billion 15tCO2e until 2015. Based on this supply-demand imbalance, CER and ERU started to collapse (Bellassen et al. 2011). This was due mainly to an overall downward trend following the economic recession of 2009 , emissions reductions due to other policies (e.g. renewable energy), as well as the inflow of international offsets (Koch et al. 2014). Prices of credits changed significantly and the fall in carbon prices combined with regulatory uncertainty on the future of the CDM in the post-2012 climate regime resulted in a drastic decrease and distrust regarding CDM as a tool for reducing GHG emissions worldwide. Africa was the continent that most suffered the market decline, which threatened the capacity to develop low-carbon projects.

After this drawback, accelerating the CDM reform became an imperative for the UNFCCC. In September 2011, the CDM executive board decided to establish a highlevel panel to review the mechanism and prepare it for the post-2012 period. The panel published the final report consisting of 51 recommendations that address not only the 16 CDM EB, but also other stakeholders including national governments, the UNFCCC and project 17 participants (UNFCCC 2012). Key issues addressed in the CDM policy dialogue were (i) streamlining the project cycle; (ii) changing the methods for determining additionality; (iii) modifying the role of the secretariat; (iv) 
improving the validation and verification model; (v) professionalization of the EB; (vi) implementation of an appeals mechanism and (vii) strengthening the current stakeholder consultation system (Classen et al. 2012).

\section{From the Paris Agreement to the Present and Towards the Global Stocktake (2015-2024)}

The year 2015 represented a milestone in taking action on climate change. In Paris, world leaders reached an agreement at the 21st Conference of the Parties (COP 21) to keep the global average temperature increase to well below $2{ }^{\circ} \mathrm{C}$ and pursue efforts to hold the increase to $1.5^{\circ} \mathrm{C}$. For the first time, all countries had to make individual, voluntary commitments to contribute to this global goal. Under the Paris Agreement, the vast majority of governments around the globe-189 countries representing $96 \%$ of global GHG-have committed to reduce their emissions by submitting the Intended Nationally Determined Contributions (INDCs).

Under the INDCs, countries determine their contributions in the context of their national priorities, circumstances and capabilities that should lead to collective actions and transformations toward a zero-carbon future. INDCs represent voluntary guidelines for governments that are intended to communicate the steps they will take to address climate change and resilience in their own countries. Some countries also communicate not only mitigation actions and steps, but how they will adapt to climate change impacts, and what support they need from, or will provide to, other countries to adopt low-carbon pathways and to build climate resilience (WRI 2019).

An important role will be played by carbon pricing in support of the efforts to decarbonize national economies (World Bank 2020). Article 6 of the Paris Agreement provides a basis for facilitating international recognition of cooperative carbon pricing. Since the entry into force of the PA in 2016, a growing number of jurisdictions are implementing or planning to implement a carbon tax or an emission trading system - a total of 57 initiatives compared to 51 in 2018 and this number is set to grow, according to countries' climate pledges (Lucatello, 2017).

As of 2019, 57 carbon pricing initiatives have been implemented. This consists of 28 ETS, spread across national and subnational jurisdictions, and 29 carbon taxes, primarily implemented on a national level. In total, as of 2019, 46 national and 28 subnational jurisdictions are putting a price on carbon. Carbon pricing initiatives implemented and scheduled for implementation cover 11 gigatons of carbon dioxide equivalent (GtCO2 e) or about 20\% of GHG emissions (World Bank, Ecofys 2019).

Most of this action has taken place in the Americas, and particularly in Canada where the federal carbon pricing approach has prompted new initiatives at the provincial level. Important developments have also occurred in other parts of the world with new carbon taxes in Singapore and South Africa-the first carbon pricing instrument implemented in Africa-and new initiatives explored in Colombia, Mexico, the Netherlands, Senegal, Ukraine and Vietnam. Countries are committed to using 
carbon pricing to meet national climate targets. One hundred eighty-five parties have submitted their Nationally Determined Contributions (NDCs) to the Paris Agreement-representing 55\% of global GHG emissions-stating that they are planning or considering the use of carbon pricing as a tool to meet their commitments. That is an increase of eight parties from 2018 (World Bank, Ecofys 2019).

Since the entry into force of the PA, the international climate regime has thus changed its character from a top-down approach based on mandatory emissions commitments to a bottom-up system of voluntary government pledges. The combination of existing, emerging and potential carbon market mechanisms can be regarded as an emerging global carbon market landscape based on differing bottom-up market-based approaches (Redmond and Convery 2015).

Currently, the overall picture of world carbon initiatives shows the following distribution: national carbon markets (ETS), offsetting mechanism and carbon taxes. Over the past few years, national and subnational carbon markets, mainly emissions trading systems have proliferated. Both developed and developing nations have introduced emissions trading as a tool to reduce emissions instead of the CDM. Offsetting against carbon taxes has also started to work in the past few years. The World Bank offers a yearly international report of the State and Trends of carbon pricing with a clear and updated mapping of carbon initiatives (WB 2019 and previous versions).

According to this same report (2019), many jurisdictions are deepening their carbon pricing ambition to better align with their climate goals, and many ETS are being created. Governments are increasingly recognizing carbon pricing as a key policy instrument to deliver on climate mitigation targets and are looking to raise carbon pricing ambition-either through price increases, removing exemptions or increased stringency. In some countries-most notably China-the CDM is being transformed into a domestic offsetting mechanism under the newly piloted national carbon trading scheme with more than 2000 projects re-validated for this purpose (Lo and Cong 2017).

In this context, Mexico has established the ETS pilot programme to sum up to the already existing worldwide experiences in carbon pricing and pointing like China to upgrade CDM and NAMAs experiences to an ETS scheme (Table 8.1).

\section{The Global Financial Architecture for Supporting Carbon Markets and ETS}

Why is external financial support needed to implement an ETS and who will finance it?

Over the past two decades, many international financial institutions, donor agencies and national development banks have supported the creation of different initiatives to build carbon trading markets under the UNFCCC process and beyond. Carbon finance is vital to achieve low-carbon, climate resilient development and emission reductions. Likewise, the global climate finance architecture is a very complex issue 
Table 8.1 Evolution of carbon markets

\begin{tabular}{|c|c|}
\hline Evolving periods & Major features \\
\hline 1997-2005: emergence & $\begin{array}{l}\text { - Parties negotiate for the definition of the flexible } \\
\text { mechanisms and for the definition of their operational } \\
\text { rules and procedures } \\
\text { - After initial testing through AIJ, the CDM, JI and IET are } \\
\text { agreed } \\
\text { - Carbon markets created and catalyzed to demonstrate the } \\
\text { potential for low cost emission reduction and compliance } \\
\text { with Kyoto targets-Environmental integrity and } \\
\text { economic efficiency of the mechanisms are studied in } \\
\text { detail }\end{array}$ \\
\hline 2006-2011: "Gold rush" & $\begin{array}{l}\text { - After the initial testing period the carbon markets start a } \\
\text { phase of great expansion } \\
\text { - EU is the main source of demand for CDM credits while } \\
\text { China and India dominate their supply } \\
\text { - Improvements to the CDM rules, with operationalization } \\
\text { of the PoA concept reducing transaction costs of } \\
\text { small-scale projects and contributing to a more balanced } \\
\text { distribution } \\
\text { - Governance and institutional setup, including capacity } \\
\text { building needs, emerge as a key element for the carbon } \\
\text { market functioning }\end{array}$ \\
\hline 2012-2014: fragmentation & $\begin{array}{l}\text { - Uncertainties on the future climate regime and lack of } \\
\text { mitigation ambition of Annex I countries affect the carbon } \\
\text { markets negatively } \\
\text { - Prices drop quickly reaching all-time low. Investors have } \\
\text { less confidence in market mechanisms-NAMAs start to } \\
\text { outscale CDM } \\
\text { - Governance and institutional setup, including capacity } \\
\text { building needs, emerge as a key element for the carbon } \\
\text { market functioning registrations and issuances, although } \\
\text { with limited numbers } \\
\text { - CDM reforms in order to reduce transaction costs for the } \\
\text { KP second commitment }\end{array}$ \\
\hline 2015-2020: post-Paris agreement & $\begin{array}{l}\text { Prices in the carbon markets are still very low. Limited } \\
\text { activities in the international carbon markets-The PA } \\
\text { brings positive developments regarding market } \\
\text { instruments through Article } 6 \text {. Detailed modalities and } \\
\text { procedures for the new mechanisms (i.e. the SDM and } \\
\text { CAs) are still to be defined-An increasing number of } \\
\text { developed and developing countries implement or plan to } \\
\text { implement carbon pricing initiatives, some of which allow } \\
\text { use of credits }\end{array}$ \\
\hline
\end{tabular}

Source Author's elaboration based on Michaelowa (2019) 
to track and monitor, as it is always evolving. ${ }^{1}$ Generally speaking, available funds for carbon initiatives flow through multilateral channels and increasingly through bilateral, regional and national climate change channels and funds. The wide range of climate finance mechanisms continues to challenge coordination and follow-up (ODI 2018).

Despite differences in the amount of money disbursed as well as technical procedures for implementing the carbon initiatives, the primary and common function for all these funds is to encourage the development of a global carbon market and support carbon pricing or other instruments like ETS, which are aimed at reducing global GHG.

A brief overview of the international financial architecture for carbon finance can help to clarify why it is important to consider carbon financial funds for launching and sustaining the future Mexican ETS.

Multilateral Development Banks (MDBs) are the first and foremost source of carbon finance initiatives. They play a prominent role in delivering multilateral climate finance. The World Bank Group (WBG) has emerged as a major actor in helping carbon initiatives around the globe. The WBG currently supports 15 individual carbon funds and facilities worldwide and it works like a trustee for those funds. The WBG has been crucial in promoting the 'proof of concept' of carbon trading schemes or Emissions Trading Systems (ETSs)—by creating the first carbon fund named "Prototype Carbon Fund" in 1999. Since then, its activities have expanded considerably: according to a 2017 report, the WBG's carbon finance portfolio reached $\$ 4.8$ billion (IEG 2017). It's worth bearing in mind that this money was used to fund different projects and initiatives, some of which include support for launching ETS in different parts of the world.

Regional banks such as the European Investment Bank, which administers the EU Global Energy Efficiency and Renewable Energy Fund (GEEREF) as a source of finance for the EU-ETS, are also important actors in funding carbon initiatives. As stated by the Joint Report on Multilateral Development Banks Climate Finance, the African Development Bank (AfDB), the Asian Development Bank (ADB), the European Bank for Reconstruction and Development (EBRD), the European Investment Bank (EIB), the Inter-American Development Bank Group (IDBG) have reported their commitment of almost US\$237 billion in climate finance since 2012, in developing and emerging economies (JR-MDB 2018). All of them are helping to boost ETS projects in their specific geographical areas.

Bilateral cooperation agencies, such as the GIZ, the German cooperation agency, are also very active in supporting efforts to build ETS in different parts of the world.

\footnotetext{
${ }^{1}$ Carbon and Climate Finance are used in this article in different ways. Carbon markets are part of the climate finance architecture. The first are economic instruments for effectively managing emissions of GHG in economically efficient ways for the society as a whole. In the absence of specific market-based mechanisms, climate finance is an essential tool to ensure that emission reduction opportunities are successfully implemented through other approaches such as "resultsbased" proejcts. Climate finance could also be used in the context of the "non-market approaches to sustainable development" mentioned in Article 6 of the Paris Agreement.
} 
GIZ acts mainly as an advisor to relevant government-level actors during the introduction of the emissions trading system. In the specific case of Mexico, as stated in the introduction of this book, GIZ has assisted Mexico's Ministry of Natural Resources in implementing the ETS.

In general, after a revision of carbon finance initiatives to support ETS around the world and specifically in emerging economies, we can say that activities financed by international or bilateral donors offer the following set of solutions:

(a) Scientific analyses and policy recommendations to inform and support decision-making authorities on the design of the ETS. This is done by previously identifying what sectors will be covered by the system as well as identifying allowed emissions limits.

(b) Technical expertise on how reinforcing national emissions gas inventories per sector and strengthening methodologies for baseline emissions at national or local level.

(c) Capacity-building and stakeholder engagement for different actors and institutions both in public and private sectors. Thus, stakeholders can assume their roles and responsibilities in the market.

(d) Academic support through scientific approaches with local epistemic communities.

(e) International dialogue and exchange with jurisdictions that already have similar systems in place in order to facilitate learning.

(f) Communications strategies to different stakeholders in order to promote awareness and the importance of ETS systems as well as their benefits.

(g) Conduction of workshops, meeting and training sessions in which the emissions trading system is discussed and if necessary, revised.

A crucial point regarding the establishment of an ETS is the delicate balance of supply and demand governance mechanisms established by the government. On the supply side, the distribution of the total supply of emissions units determined depends upon several factors. Supply in particular depends on parameters set by policymakers, for example, by clearly establishing from the beginning the level at which the cap is set, or through the rules set relating to offsets, banking and borrowing, or linking (ICAP 2018).

On the demand side, total demand for emissions units in an ETS depends largely on the behaviour and characteristics of market stakeholders and depends on shocks unrelated to ETS design features, such as the level of emissions under Business as Usual (BAU) scenarios, or the costs of abating emissions within the covered sectors.

A final and very important issue for financing ETS design and implementation has to do with enforcement. Any ETS acts with strict and rigorous rules for market oversight and enforcement. Emissions must be traced clearly and reported consistently. A lack of compliance and oversight may threaten the environmental integrity of the system and the basic functionality of the market, deriving in losses and damages for all stakeholders involved. An important prerequisite for effective compliance must identify all participating entities which are regulated by the system. Government 
has to be very effective to develop specific processes and features to identify new regulated entities, especially private firms involved in the ETS.

\section{Lessons from and for Mexico: The Creation of the Financial Funds for Technical Assistance and Financing of CDM Projects (FOMECAR)}

Following the international evolution of carbon markets, Mexico has paralleled many international phases and steps of the above described carbon history. Particularly, with the "golden era" of carbon markets and under increasing awareness by the Mexican government, both private sector and the Mexican scientific community began to work on climate change mitigation challenges' and their consequences for the country.

An important cornerstone for Mexican mitigation policy was the Clean Development Mechanism (CDM) scheme that was an opportunity for the Mexican private and public sectors both to participate in a regulated market in the emission of CERs and thereby contribute to efforts to reduce GHG emissions. At the same time, it could also serve as an additional source of revenue in the implementation of those projects by cashing CERs derived from international projects.

The CDM was a clear economic instrument to encourage the participation of the public and private sectors in efforts to reduce greenhouse gases and in the implementation of mitigation measures. In institutional terms, at the end of 2006, Mexico established the Mexican Carbon Fund (FOMECAR), which was hosted at the Banco Nacional de Comercio Exterior, S.N.C., (Bancomext) and under the decided support of the Secretaría de Medio Ambiente y Recursos Naturales (SEMARNAT).

FOMECAR was created as a trust within Bancomext through the initial contribution made by the Mario Molina Center for Strategic Energy Studies, and initially received contributions from public and private, national and foreign institutions.

From Bancomext's perspective, FOMECAR involved different features. (1) It constituted a typical development-banking product that, once it has taken advantage of the market niche, would be operated by private banks. (2) It encouraged the development of investment projects with multiplier effects for the Mexican economy; (iii) It supported the export of the Mexican mitigations of greenhouse gases or carbon credits generated through the projects, and it complemented the range of financial products offered by the Mexican government (Crespo-Chiapas 2018).

For SEMARNAT, the Mexican Carbon Fund meant providing assistance and technical and financial resources to promote the development of CDM projects before private initiative and public sector entities. It also helped to fulfil the country's international commitments regarding climate change before the United Nations Framework Convention on Climate Change (UNFCCC) (Crespo-Chiapas 2018).

Through this trust, a selection of eligible projects for support was identified, resources were provided so that participants could comply with the strict stages 
established in the CDM so that their project would be eligible to receive CERs, providing technical advice and monitoring over the implementation process.

FOMECAR provided non-refundable financial resources by assuming the risk should the project not achieve its certification, which would be reimbursed by the beneficiaries once the project has been developed and the stages have been completed. At the end of this process, the trust received its issuance of CERs from the United Nations Board.

For the purposes of this article, the functions of FOMECAR can be summarized as follows:

- Organizing outreach events, pays to generate a culture of clean technologies in the country

- Supporting preparation of CDM projects with technical assistance and financial resources

- Operating mandates to promote and structure CDM projects (Heredia 2011).

Thus, the Mexican Development Bank became involved with resources and technical assistance to provide to the public and private sectors in the monitoring of projects focused on reducing GHGs emissions, becoming a channel for the distribution of resources for this purpose.

FOMECAR not only provided resources for monitoring the various stages and protocols established in the CDM scheme but it could also provide resources for financing the project itself, that is, for the implementation of projects such as the following: renewable energy projects and efficient use of energy, fuel change projects, waste management projects in landfills and waste from livestock farms, transportation projects and forest projects.

In carrying out its activities, FOMECAR was established as an instrument of technical assistance and training in the subject, both for medium-sized companies as well as transnational corporations and commercial banks, receiving donations from the governments of European countries and counting on the support of multilateral banks.

FOMECAR's results from the period 2006 to 2011 included several outcomes. On one side, it provided technical assistance to $800 \mathrm{CDM}$ project initiatives, from simple proposals for sustainable projects to complex projects with an impact on GHG reductions from PEMEX and CFE. Secondly, it was a major tool for showing Mexico's commitment to mitigation in specialized seminars and exhibitions. Thirdly, it was considered an instrument for financial assistance to five projects with expected reductions of 1.3 million tCO2e, for a total amount of USD 400,000 to support CDM documentation, validation and registration expenses. The investment amount necessary to implement these projects represented USD 123 million (Lokey 2009). Despite these efforts, its scope was limited since none of its projects managed to register the CDM, suffering the enormous bureaucracy established to finally obtain the CERs, along with the 2008-2009 economic recession and the fall of the carbon markets. 


\section{The Experience of FOMECAR and the New Emissions Trading System in Mexico}

It is noteworthy that within the agreement establishing the preliminary bases of the emissions trading system pilot programme in Mexico, its Chap. 4 provides for the existence and development of a flexible compliance mechanism, which we could summarize as follows:

- The flexible mechanism may consist of a compensation scheme through eligible mitigation projects or activities or the recognition of early actions for mitigation projects or activities that have received external compensation credits before the entry into force of the pilot programme.

- The secretariat will establish a compensation scheme, defining which compensation protocols, national or international, can be used by the interested parties to develop the eligible mitigation projects or activities, and can develop their own protocols.

- The secretariat may issue compensation credits to those activities that reduce or prevent emissions or increase absorption of said gases, in compliance with the protocols provided.

- In addition to being carried out under said protocols, in order to obtain said compensation credits, the activities in question must be carried out in the national territory, be validated and verified by a greenhouse gas emission verification and validation body and be registered in the National Registry of Emissions provided for in the General Law on Climate Change.

- Participants may only offset with offset credits up to $10 \%$ of their allowances with delivery obligations during the pilot programme.

That is why, given that the existence of flexible compliance mechanisms is provided for in the emerging emissions trading system in Mexico, it is estimated that the experience of FOMECAR constitutes a benchmark that can be considered in its replication. Either through the involvement of Mexican development banks or international and regional multilateral banks and the contribution of public and private resources together with technical assistance from international cooperation (like GIZ), a new financing scheme can be created for projects that may issue compensation credits that participate in this emissions trading system.

Given the current circumstances of government-imposed economic restrictions as well as the selectivity in channelling financial resources that the COVID-19 pandemic may imply, it is crucial to rethink new financial mechanisms for supporting ETS implementation after the pilot phase. The creation of coordinating entities and efforts both in generating new projects that can reduce GHG emissions and providing technical and financial assistance in their implementation are of utmost relevance for these flexible compliance mechanisms to see the light within the Mexican market.

The very dissemination of the existence of a flexible compliance mechanism within the emissions trading system pilot programme in Mexico and its possibilities and scope as an incentive for the implementation of $\mathrm{GHG}$ emission reduction projects 
can open a window of opportunity. Additional resources could be transferred in for commercialization of compensation through the replication of financial funds such as FOMECAR. Its replication, with corresponding adjustments, seems somewhat relevant when considering implementation of the Mexican ETS.

\section{Conclusions}

In this article, the authors offered a first attempt to understand how past experiences for technical support for climate mitigation projects such as the CDM can be used as lesson for the new ETS in Mexico. Building on the experience from FOMECAR and other internationally established ETS, some interesting reflections can be shared before the Mexican ETS will take shape.

Major experiences drawn from the CDM point to the following issues: any mitigation policy instruments must be supported by robust, transparent, and constantly updated information on emissions by sector. This is crucial for Mexico, where major stakeholders are public energy companies such as PEMEX and CFE.

Secondly, in terms of setting cap's stringency, the government and technical advisors financed by international funds need to set clear and affordable reduction targets via the ETS. Further, these targets should be stringent enough to guarantee significant contribution to the achievement of the Mexican INDC. Thirdly, setting the procedures and mechanisms to facilitate, promote and enforce compliance to achieve the ETS objectives should be a priority since it was not the case for the CDM and NAMAs.

Finally, in the process of setting up the ETS, a national fund like FOMECAR or similar should be implemented as an instrument of technical assistance and training in the subject, both for medium-sized companies as well as stakeholders involved in the market generated by the ETS.

\section{References}

Bakhtiari F, Gagnon- Lebrun L, Olsen KM, Bizikova L, Harris M, Boodoo Z (2015) Framework for measuring sustainable development in NAMAs. https://unepdtu.org/publications/frameworkfor-measuring-sustainable-development-in-namas/

Bellassen V, Stephan N, Leguet B (2011) Will there still be a market price for CERs and ERUs in two years time? CDC Climat, Paris

Börzel TA, Risse T (2002) Public-private partnerships: effective and legitimate tools of international governance?

Classen M, Arumugam P, Gillenwater M, Olver C, Lo M, de Chazournes LB, Swanepoel E (2012) $\mathrm{CDM}$ policy dialogue research programme research area: governance. CDM Policy Dialogue. UNFCCC, Bonn

Crespo MT (2018) Los Instrumentos de Mercado en la Política de Cambio Climático, el caso de México 2005-2015. Universidad Nacional Autónoma de México, Facultad de Economías, División de Estudios de Posgrado. Tesis de Doctorado. Febrero de 2018 
Fan ZOU, Hui YANG, Qin YL (2011) Thinking on the development of "Carbon Finance" in Commercial Banks of China. Energy Procedia 5:1885-1892

Haigh M (2011) Climate policy and financial institutions. Clim Policy 11(6):1367-1385

Hamrick K, Gallant M (2017) Unlocking potential: state of the voluntary carbon markets 2017. Forest Trends' Ecosystem Marketplace, Washington, DC

Heredia M (2011). https://www.pymempresario.com/2011/03/los-bonos-de-carbono-al-alcancede-inversionistas-mexicanos/

IEG (2017) Approach paper "Cool Markets" for GHG emission reduction in a warming world: evaluation of World Bank Group's support to carbon finance

JR (2018) Joint report on multilateral development banks's climate finance. file:///C:/Users/slucatello/Downloads/2018-joint-report-on-mdbs-climate-finance.pdf

Karani P, Gantsho M (2007) The role of development finance institutions (DFIs) in promoting the clean development mechanism (CDM) in Africa. Environ Dev Sustain 9(3):203-228

Koch N, Fuss S, Grosjean G, Edenhofer O (2014) Causes of the EU ETS price drop: recession, CDM, renewable policies or a bit of everything? New evidence. Energy Policy 73:676-685

Lo AY, Cong R (2017) After CDM: domestic carbon offsetting in China. J Clean Prod 141:13911399

Lucatello S (2017) La gobernanza de los mercados de carbono: del Protocolo de Kioto al acuerdo de Paris. In "Gobernanza Climática en México: Aportes para la consolidación estructural de la participación ciudadana en la política climática nacional”, vol 2. PINCC-UNAM, México. http:// www.pincc.unam.mx/IMG/pdf_gobernanza/vol2.pdf

Lucatello S (2011) The clean development mechanism and sustainable development in Mexico: what contribution? Lambert Publishing, UK

Mehling M, Mielke S (2012) Market-based instruments for greenhouse gas mitigation in Brazil: experiences and prospects. Carbon Clim Law Rev 6(4):365-372

Michaelowa A (2016) Carbon markets or climate finance? Low carbon and adaptation investment choices for the developing world. Ed. Routledge, London

Michaelowa A, Shislov I, Brescia D (2019) Evolution of international carbon markets: lessons for the Paris agreement. Zurich Open Repository and Archive. https://www.zora.uzh.ch/id/eprint/ 175354/1/ZORA17354.pdf

ODI (2018) Global climate financial architecture. https://www.odi.org/sites/odi.org.uk/files/res ource-documents/11850.pdf

Redmond L, Convery F (2015) The global carbon market-mechanism landscape: pre and post 2020 perspectives. Clim Policy 15(5):647-669

Shishlov I, Bellassen V (2016) Review of the experience with monitoring uncertainty requirements in the clean development mechanism. Clim Policy 16(6):703-731

Shishlov I, Morel R, Bellassen V (2016) Compliance of the parties to the Kyoto protocol in the first commitment period. Clim Policy 16(6):768-782

Spalding-Fecher R (2011) What is the carbon emission factor for the South African electricity grid? J Energy South Afr 22(4):8-14

UNCTAD (2009) The state of play of the clean development mechanism review of barriers and potential ways forward. https://unctad.org/en/Docs/ditcbcc20093_en.pdf

UNFCCC (2012) Climate change, carbon markets and the CDM: a call to action. CDM Policy Dialogue. UNFCCC, Bonn

Wara M (2008) Measuring the clean development mechanism's performance and potential. UCLA law review. University of California, Los Angeles. School Law 55(6)

Weber RH, Darbellay A (2011) The role of the financial services industry in the clean development mechanism: involving private institutions in the carbon market. Int J Priv Law 4(1):32-53

World Bank, Ecofys (2012) State and trends of carbon markets 2012. World Bank, Washington, DC World Bank, Ecofys (2019) State and trends of carbon pricing 2019. World Bank, Washington, DC 
Open Access This chapter is licensed under the terms of the Creative Commons Attribution 4.0 International License (http://creativecommons.org/licenses/by/4.0/), which permits use, sharing, adaptation, distribution and reproduction in any medium or format, as long as you give appropriate credit to the original author(s) and the source, provide a link to the Creative Commons license and indicate if changes were made.

The images or other third party material in this chapter are included in the chapter's Creative Commons license, unless indicated otherwise in a credit line to the material. If material is not included in the chapter's Creative Commons license and your intended use is not permitted by statutory regulation or exceeds the permitted use, you will need to obtain permission directly from the copyright holder.

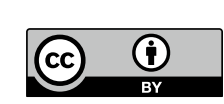

